University of Nebraska - Lincoln

DigitalCommons@University of Nebraska - Lincoln

2006

Force protection using composite sandwich structures

R. L. Sierakowski

M. L. Hughes

Follow this and additional works at: https://digitalcommons.unl.edu/usafresearch

Part of the Aerospace Engineering Commons

Sierakowski, R. L. and Hughes, M. L., "Force protection using composite sandwich structures" (2006). U.S. Air Force Research. 30.

https://digitalcommons.unl.edu/usafresearch/30

This Article is brought to you for free and open access by the U.S. Department of Defense at DigitalCommons@University of Nebraska - Lincoln. It has been accepted for inclusion in U.S. Air Force Research by an authorized administrator of DigitalCommons@University of Nebraska - Lincoln. 


\title{
Force protection using composite sandwich structures
}

\author{
R.L. Sierakowski ${ }^{\text {a }}$, M.L. Hughes ${ }^{b, *}$ \\ a Air Force Research Laboratory, Munitions Directorate, AFRL/MN CA-N, 101 W. Eglin Boulevard, Ste. 135, Eglin AFB, FL 32542-6810, United States \\ b Auburn University, Department of Civil Engineering, 238 Harbert Engineering Center, Auburn, AL 36849-5337, United States
}

Received 23 March 2006; accepted 28 March 2006

Available online 5 June 2006

\begin{abstract}
In the recent past, advances have been made in the attempt to utilize composite materials as components in protective structures such as those employed by the Air Force to secure critical military assets. In such applications, where lightweight materials that exhibit large levels of energy absorption and high strength/stiffness characteristics are desirable, composite sandwich constructions offer an attractive solution.

In an attempt to evaluate the suitability of certain sandwich structures for use in force protection applications, several sandwich constructions with somewhat novel core materials were identified. A group of thermoplastic core materials have been developed that possess features of both a dense elastic solid and a foam type material. This class of core materials incorporates sloping cell walls, rather than the traditional parallel cell wall structure present in, say, a regular aluminum honeycomb. This feature, along with the increased surface area connectivity present between cells (produced by the forming process used to create the core materials) integrates surrounding cells into what may be described as an enhanced hexagonal single unit cell structure.

To develop a preliminary understanding of the response of these enhanced cellular materials to the various loading regimes that could be encountered in a protective structure, a series of static and dynamic tests were conducted at Tyndall Air Force Base. A complete description of the novel core materials, as well as the results of the static and dynamic tests, will be presented in this paper.
\end{abstract}

(C) 2006 Elsevier Ltd. All rights reserved.

Keywords: C. Sandwich; B. Mechanical properties; B. Strength; A. Structural materials; Cellular structure

\section{Introduction}

"Mobility is the sinew of global reach - and a capability that will serve our interests well into the future..." These words of former United States Air Force Secretary Donald Rice in his white paper entitled "Global Reach - Global Power: The Evolving Air Force Contribution to National Security," [1] formed one of the principal tenants of the Air Force strategic architecture of the 1990s. Though the world political environment has changed dramatically since that document was written, the Air Force's commitment to "providing the mobility to rapidly position and reposition forces in any environment, anywhere in the world," [2] has not. The Air Force must maintain, and ever advance, its

\footnotetext{
${ }^{*}$ Corresponding author. Tel.: +1 334844 6261; fax: +1 3348446290.

E-mail address: hughema@eng.auburn.edu (M.L. Hughes).
}

ability to rapidly deploy and sustain troops in the farreaching theaters of operation demanded by current national requirements.

In the past, massive concrete structures were frequently used by the military to protect personnel and critical equipment. The aforementioned requirement for rapid mobility has, of course, rendered these structures impractical. New materials have been sought that can be transported easily and used for rapid construction, while maintaining adequate levels of protection. Composite materials that have traditionally been used in aerospace applications may supply a viable answer to this demand.

In the search for lightweight, durable construction materials that would satisfy the requirements for military protective structures, an investigation was conducted at Tyndall Air Force Base, FL, to determine the suitability of a somewhat novel honeycomb sandwich composite 
construction. The forming process used to shape the core material produces a triangular honeycomb cell structure that is lightweight, yet has sufficient flexural and shear integrity to be considered for use in protective structures.

\section{Structure of the core materials}

The thermoplastic honeycomb core materials under consideration were developed by the Norfield Corporation, and are currently marketed by Phelps Engineering Plastics, Inc. [3]. The unique feature of these core materials is that each consists of a triangular honeycomb cell structure with sloping walls, which are geometrically interlocked. The forming technique used to shape the lightweight sandwich core materials (known as NorCore ${ }^{\circledR}$ ) is based on the principle that when a thermoplastic polymer in either a sheet or extruded form is placed between heated mold surfaces, an adhesion occurs between the polymer and heated platens when a slight amount of pressure is applied. By drawing the platens apart, the viscous polymer flows, extends, and forms a geometric core patterned after the design on the mold surfaces. Unlike classic parallel wall honeycomb cores, the new material has angular walls with a cell structure that is a function of the expansion height and the mold surface design. This feature, along with the increased surface area connectivity present between cells (over that present in parallel wall honeycomb cores) integrates surrounding cells into what may be described as an enhanced hexagonal single unit cell structure. In Fig. 1, a cross section of the sloping wall structure is pictured (the black object is merely a clamp holding the core material), while in Fig. 2a, a plan view of the core structure is shown. In Fig. 2b, a closeup of the enhanced hexagonal unit cell is highlighted by the dashed lines. One can observe that each cell (opening) is geometrically linked to the six cells surrounding it by the sloping walls, creating what is effectively a hexagonal cell structure.

This stretched core structure leads to the potential for an enhanced flexural and shear integrity, achieved via the wide flange area above the periphery of each open cell that is obtained through the forming process. This flange area and the structure of the angular walled core material offer new design possibilities. One desirable feature of the unique

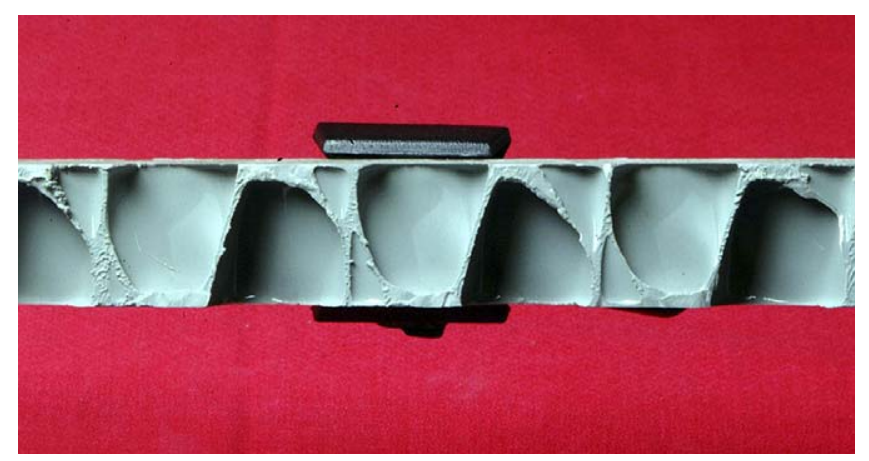

Fig. 1. Sloping wall core structure.

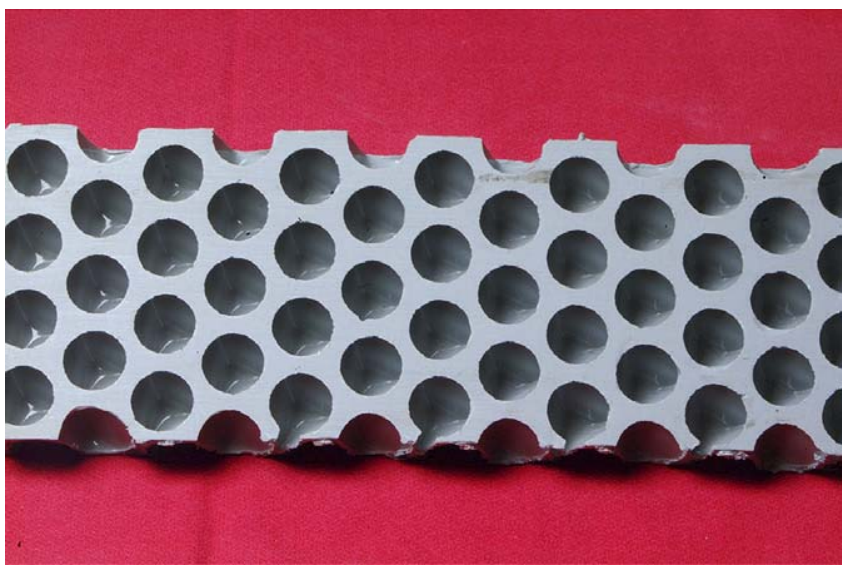

Fig. 2a. Plan view of core material.

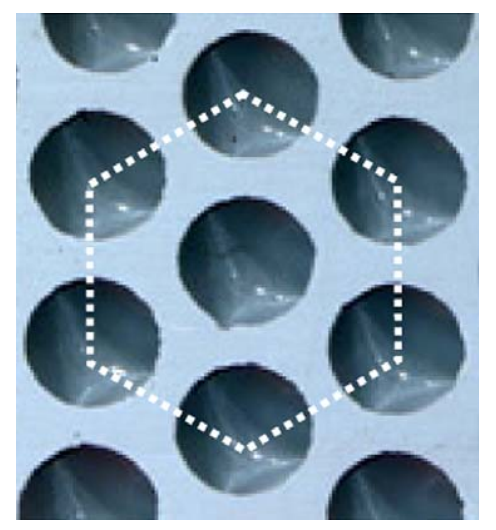

Fig. 2b. Enhanced hexagonal unit cell.

structure is an ability to resist impact loads efficiently. It is anticipated that an increased energy absorption capability over parallel wall cores can be realized and attributed to the peripheral surface area formed during the shaping process of the stretched honeycomb core.

\section{Mechanical testing}

Six thermoplastic core materials were chosen for testing to develop an understanding of their response to the various loading regimes that could be encountered in a protective structure. The three materials were polycarbonate, a polycarbonate regrind, polystyrene, ABS regrind, highimpact polystyrene, and suryln (which, incidentally, has also been employed in golf ball construction). In their structural form, these cores are sandwiched between two thin and stiff sheets of facing material; some facing materials that have been utilized with NorCore ${ }^{\circledR}$ materials in the past are aluminum, steel, medium density fiberboard, plywood, acrylic sheeting, high-pressure laminates, and fiber reinforced plastics. For this investigation, tests were performed with and without facing materials; in all cases in which facing sheets were used, the material was $0.032^{\prime \prime}$ $(0.813 \mathrm{~mm})$ thick aluminum. 
While some manufacturer's data pertaining to the core materials are available, little information was given regarding their dynamic properties. To preliminarily assess the materials' suitability for use in protective structures, a series of static and dynamic compressive tests were conducted on the three core materials. The tests were performed for varying core thicknesses as well as for several initial starting thicknesses of the drawing sheet.

\subsection{Static testing}

The static flatwise compressive strength of the sandwich cores was determined by following ASTM Standard C365 [4] and Mil-Standard 401-B, Section 5. Although these standards are based on the premise that the core ligaments are parallel and perpendicular to the core thicknesses and facings, respectively, they were used for these unique materials whose ligaments are set at an angle to the core and facing directions since no directly applicable standards exist. After considering the guidelines given on the number of cells which should be included in a test sample, 2" $(50.8 \mathrm{~mm})$ diameter specimens were chosen for the static and dynamic tests (described in the following section). This dimension allowed (in most cases) inclusion of one complete "opening" on one side of the specimen, while the edge diameter of the specimen cut through a number of openings on the other side, due to the sloped angle of the cell walls (as shown in the post-test, crushed specimens presented in Fig. 3). Static tests were conducted using an MTS hydraulic load frame on bare core specimens, as well as on cores in the stabilized state (faced with $0.032^{\prime \prime}$ $(0.813 \mathrm{~mm})$ thick aluminum on both sides). Table 1 presents a summary of the static testing results, where data are reported based on a minimum of three tests per material, with specimen core size and starting thicknesses of thermoplastic sheet reported. The values of maximum com-
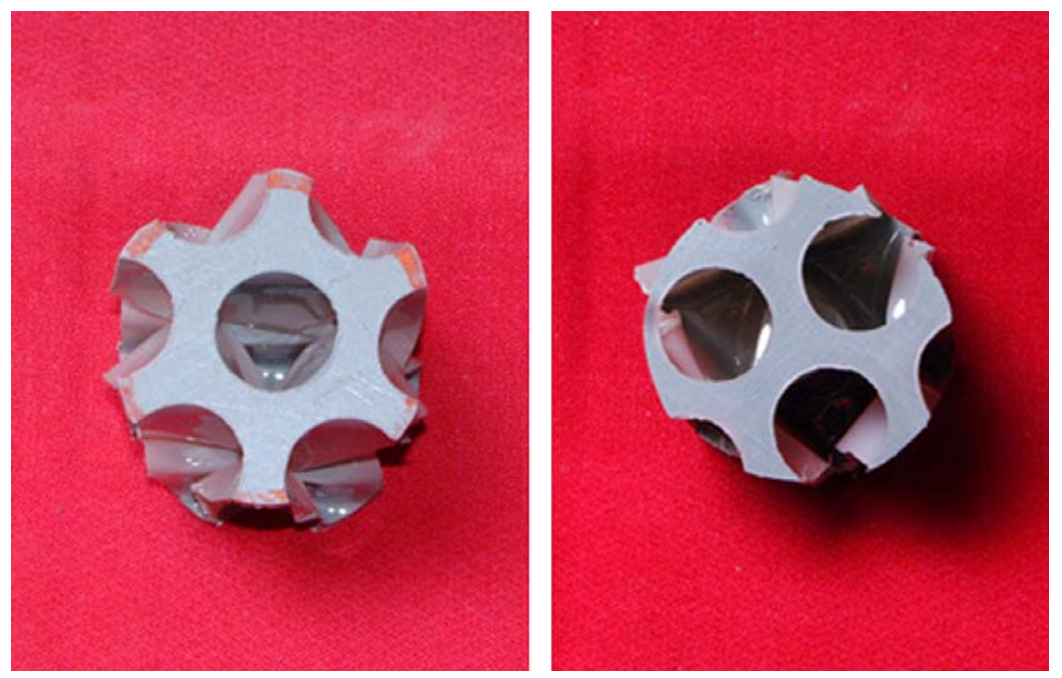

Fig. 3. Opposing faces of typical $2^{\prime \prime}(50.8 \mathrm{~mm})$ diameter core specimen used in flatwise compressive testing.

Table 1a

Static testing results (English)

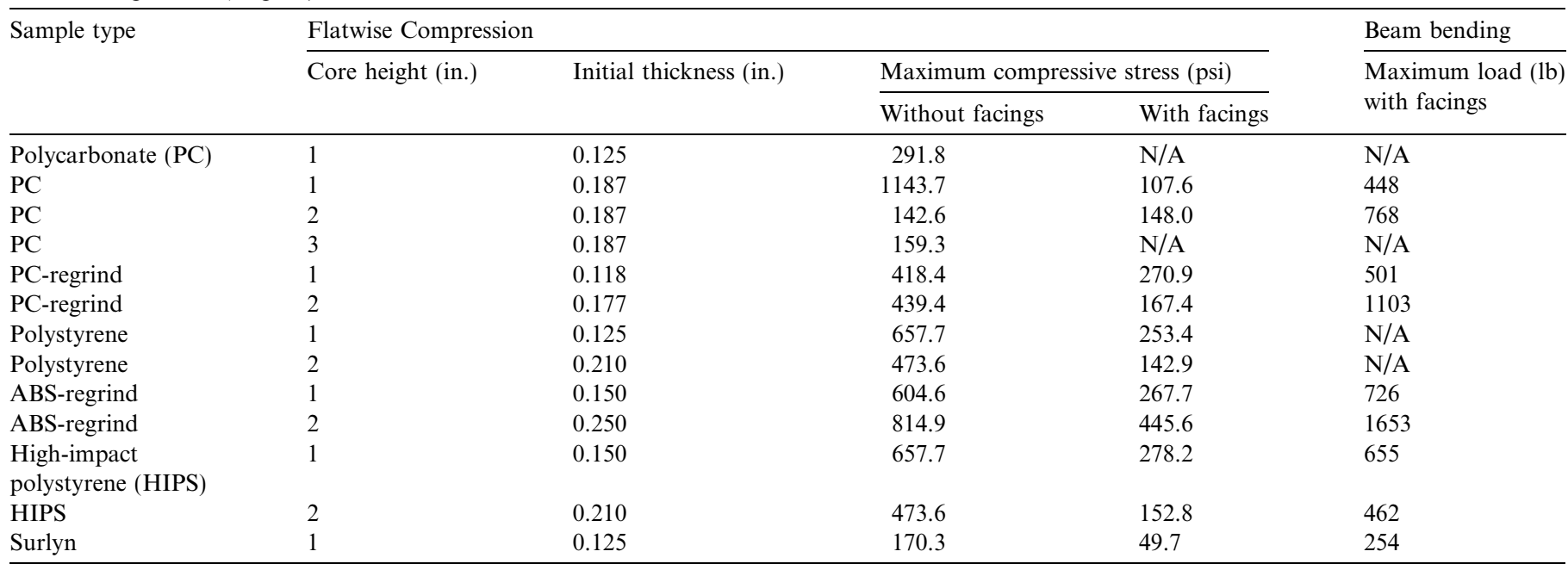


Table $1 b$

Static testing results (Metric)

\begin{tabular}{|c|c|c|c|c|c|}
\hline \multirow[t]{3}{*}{ Sample type } & \multicolumn{4}{|c|}{ Flatwise compression } & \multirow{3}{*}{$\begin{array}{l}\frac{\text { Beam bending }}{\text { Maximum load }(\mathrm{N})} \\
\text { with facings }\end{array}$} \\
\hline & \multirow{2}{*}{$\begin{array}{l}\text { Core height } \\
(\mathrm{mm})\end{array}$} & \multirow{2}{*}{$\begin{array}{l}\text { Initial thickness } \\
(\mathrm{mm})\end{array}$} & \multicolumn{2}{|c|}{ Maximum compressive stress (MPa) } & \\
\hline & & & Without facings & With facings & \\
\hline Polycarbonate (PC) & 25.4 & 3.175 & 2.0 & N/A & N/A \\
\hline $\mathrm{PC}$ & 25.4 & 4.750 & 7.9 & 0.7 & 1993 \\
\hline $\mathrm{PC}$ & 50.8 & 4.750 & 1.0 & 1.0 & 3416 \\
\hline $\mathrm{PC}$ & 76.2 & 4.750 & 1.1 & N/A & N/A \\
\hline PC-regrind & 25.4 & 2.997 & 2.9 & 1.9 & 2229 \\
\hline PC-regrind & 50.8 & 4.496 & 3.0 & 1.2 & 4906 \\
\hline Polystyrene & 25.4 & 3.175 & 4.5 & 1.7 & N/A \\
\hline Polystyrene & 50.8 & 5.334 & 3.3 & 1.0 & N/A \\
\hline ABS-regrind & 25.4 & 3.810 & 4.2 & 1.8 & 3229 \\
\hline ABS-regrind & 50.8 & 6.350 & 5.6 & 3.1 & 7353 \\
\hline High-impact polystyrene (HIPS) & 25.4 & 3.810 & 4.5 & 1.9 & 2914 \\
\hline HIPS & 50.8 & 5.334 & 3.3 & 1.1 & 2055 \\
\hline Surlyn & 25.4 & 3.175 & 1.2 & 0.3 & 1130 \\
\hline
\end{tabular}

pressive stress reported for bare core specimens are estimates, based on the maximum compressive load (measured) divided by an average "reduced" surface area, to account for the openings present on the core faces. Maximum compressive stress values reported for specimens with facings were computed in the traditional sense, by dividing the maximum load attained by the total surface area of the $2^{\prime \prime}(50.8 \mathrm{~mm})$ diameter specimen.

In addition to the flatwise compression tests, a series of beam bending tests were conducted on some of the stabilized thermoplastic sandwich configurations. To execute these tests, a jig was constructed and fitted between the loading platens of the hydraulic testing machine, to achieve a center point loading configuration. Beam dimensions in each case were as indicated in Fig. 4, and core thicknesses of $1^{\prime \prime}(25.4 \mathrm{~mm})$ and $2^{\prime \prime}(50.8 \mathrm{~mm})$ were tested. Results of the beam bending tests are presented in Table 1 .

\subsection{Dynamic testing}

Dynamic compressive tests were conducted on a $2^{\prime \prime}$ $(50.8 \mathrm{~mm}$ ) diameter Split Hopkinson Pressure Bar (SHPB) located at Tyndall AFB, FL (which has been moved, and is presently located at Eglin AFB, FL). The system operates using a striker bar, launched by a gas gun, that impinges on an instrumented incident bar. Compressive pulses, whose magnitudes are related to the velocity of the striker bar, and whose duration depends on the bar modulus, are generated in both bars. When the compressive pulse reaches the specimen (which is sandwiched between the incident bar and another bar of like diameter, called the transmitter bar), part of the pulse is reflected and part is transmitted through the specimen. The cross-sectional area and the mechanical behavior of the specimen determine the exact shape of the reflected and transmitted pulses, recorded via strain gages affixed to the incident and transmitter bars. A record of the strain-time history of the pulses at the incident and transmitter bar strain gage sites allows for determination of the dynamic response of the specimen. Results of dynamic tests on the honeycomb core materials, with and without facings, are summarized in Table 2.

\section{Discussion}

Several interesting points can be made regarding the test results presented in Tables 1 and 2. First, and most noticeable, is the fact that the presence of facings for the stabilized core samples did not, in most cases, increase the maximum compressive stress achieved by the test specimens, under the same loading conditions. Recall that for samples without facing materials, only a fraction of the complete surface area of the $2^{\prime \prime}(50.8 \mathrm{~mm})$ diameter samples

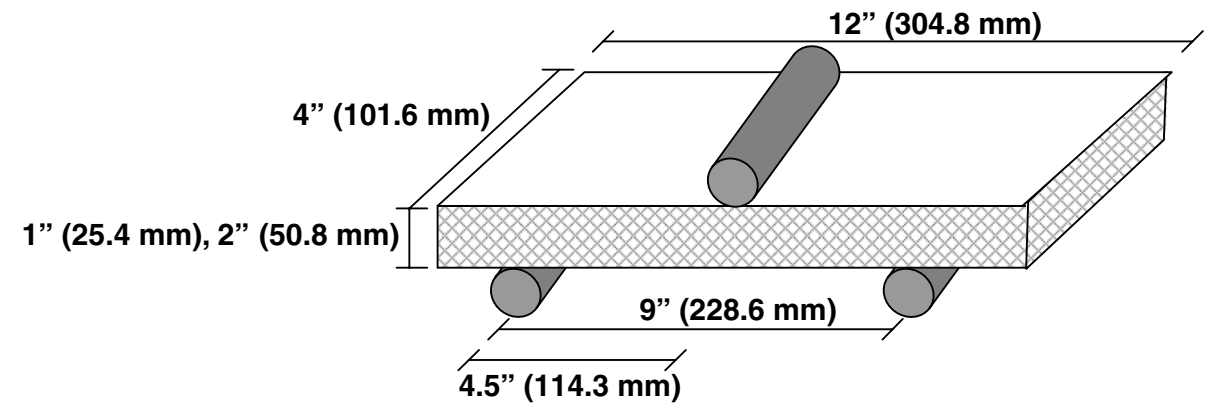

Fig. 4. Static beam bending configuration. 
Table $2 \mathrm{a}$

Dynamic testing results (English)

\begin{tabular}{lllll}
\hline Sample type & \multicolumn{3}{l}{ Flatwise compression } & \\
\cline { 2 - 5 } & $\begin{array}{l}\text { Core } \\
\text { height (in.) }\end{array}$ & $\begin{array}{l}\text { Initial } \\
\text { thickness (in.) }\end{array}$ & $\begin{array}{l}\text { Maximum } \\
\text { compressive } \\
\text { stress (psi) }\end{array}$ \\
\cline { 3 - 6 } & & & Without & With \\
& & & facings & facings \\
\hline PC & 1 & 0.187 & 382.8 & 137.8 \\
PC & 2 & 0.187 & 348.0 & N/A \\
PC-regrind & 1 & 0.118 & 234.9 & N/A \\
PC-regrind & 2 & 0.177 & 234.9 & N/A \\
Polystyrene & 1 & 0.125 & N/A & 114.6 \\
Polystyrene & 2 & 0.210 & N/A & 159.5 \\
ABS-regrind & 1 & 0.150 & 410.4 & 478.5 \\
ABS-regrind & 2 & 0.250 & 484.3 & 609.0 \\
High-impact & 1 & 0.150 & N/A & 362.5 \\
polystyrene (HIPS) & & & & \\
HIPS & 2 & 0.210 & 192.9 & 493.0 \\
Surlyn & 1 & 0.125 & 113.1 & 88.5 \\
\hline
\end{tabular}

Table $2 b$

Dynamic testing results (Metric)

\begin{tabular}{lllll}
\hline Sample type & \multicolumn{3}{l}{ Flatwise compression } & \\
\cline { 2 - 5 } & $\begin{array}{l}\text { Core } \\
\text { height } \\
(\mathrm{mm})\end{array}$ & $\begin{array}{l}\text { Initial } \\
\text { thickness } \\
(\mathrm{mm})\end{array}$ & $\begin{array}{l}\text { Maximum } \\
\text { compressive } \\
\text { stress (MPa) }\end{array}$ \\
\cline { 3 - 5 } & & & Without & With \\
& & & facings & facings \\
\hline PC & 25.4 & 4.750 & 2.6 & 1.0 \\
PC & 50.8 & 4.750 & 2.4 & N/A \\
PC-regrind & 25.4 & 2.997 & 1.6 & N/A \\
PC-regrind & 50.8 & 4.496 & 1.6 & N/A \\
Polystyrene & 25.4 & 3.175 & N/A & 0.8 \\
Polystyrene & 50.8 & 5.334 & N/A & 1.1 \\
ABS-regrind & 25.4 & 3.810 & 2.8 & 3.3 \\
ABS-regrind & 50.8 & 6.350 & 3.3 & 4.2 \\
High-impact & 25.4 & 3.810 & N/A & 2.5 \\
polystyrene (HIPS) & & & & \\
HIPS & 50.8 & 5.334 & 1.3 & 3.4 \\
Surlyn & 25.4 & 3.175 & 0.8 & 0.6 \\
\hline
\end{tabular}

were in contact with the loading platens. Thus, a reduced surface area (based on an average area for the openings) was computed for the unfaced samples to account for the "missing" bearing surface. Certainly more rigorous measurement of the actual area of the bearing surface for each specimen would increase the accuracy of the reported stresses, but the trend would remain the same. In many cases, the maximum loads reached by the unfaced cores were greater than those reached by their faced counterparts, so even if the full surface area (of a $2^{\prime \prime}(50.8 \mathrm{~mm})$ diameter circle) of the unfaced specimens had been used to compute the maximum stress, it would still have been higher than that achieved by the corresponding faced specimen. This is a somewhat nonintuitive result, and requires further investigation.

Another observation to be made is that, in many cases, increasing core height from $1^{\prime \prime}(25.4 \mathrm{~mm})$ to $2^{\prime \prime}(50.8 \mathrm{~mm})$ did not correspondingly increase the maximum stress achieved, but decreased it instead. This response could be attributed to a buckling-type behavior. Perhaps for the materials in which this trend was displayed, the $2^{\prime \prime}$ $(50.8 \mathrm{~mm})$ core height represented a slender member, and the specimen buckled before reaching the load level that the $1^{\prime \prime}(25.4 \mathrm{~mm})$ core height specimen was able to carry. Such a result indicates that an analysis should be made of each material to determine its maximum efficient core height for its intended purpose.

Although limited dynamic data were available, observation of Table 2 shows that, in most cases, for corresponding core materials and heights, the dynamic compressive stress was greater than that for the static counterparts (Table 1). This is consistent with the trends that characterize many metals, as well as some geologic materials, that materials loaded at high strain rates can support higher loads than those loaded quasistatically. For many materials, there is a threshold strain rate above which this strengthening occurs; certainly more extensive testing would be required to determine the threshold strain rate for these core materials. For the data reported in Table 2 , strain rates ranged from approximately $60 / \mathrm{sec}$ to $140 /$ sec. In comparison, the quasistatic data reported in Table 1 were collected at a strain rate of approximately $10^{-6} / \mathrm{sec}$.

Results of the beam bending tests indicate that PCregrind and ABS-regrind may be promising candidates for further study. The somewhat wide variation in test results may indicate that drawing conclusions for this group of thermoplastic core materials as a whole is not totally appropriate. What is perhaps concluded from this preliminary test series is that, based on simple tests of the type performed here, one to three of the most promising materials should be identified for protective structure purposes, then a more comprehensive testing program should be conducted to study each individual material for its suitability.

\section{Summary}

A series of static and dynamic compressive tests were conducted on a set of novel thermoplastic core materials to preliminarily assess their utility for inclusion in protective structures. Lightweight sandwich constructions offer an attractive alternative to massive concrete bunkers, lending themselves ideally to portability for today's mobile force structure. The core materials possess a novel cellular structure, potentially combining the performance of a traditional honeycomb core with some elements of an open foam material.

The forming process for these materials lends itself well to developing controls on two key parameters associated with cellular structure configurations, namely cell wall thickness and relative density. It is also important to note that the cell structure, as formed, can lead to inherent isotropy or anisotropy, depending on the particular geometrical pattern chosen for the cells. As an example, for 
mechanical properties (e.g. Young's modulus), a hexagonal cell geometry leads to essentially isotropic values, whereas square cells lead to extreme anisotropy. The forming process used for these materials would allow one to choose a certain mold shape, and therefore a certain cell structure and isotropy condition, based on the intended function.

Although the preliminary series of tests reported here did provide useful data of characterization of the mechanical properties of the novel core materials and sandwich structures, more extensive testing is definitely called for. Dynamic testing is of particular interest since the "realworld" loadings of interest to the Air Force for protective structure purposes will be dynamic in nature. Certainly tests that measure energy absorption capability would provide very constructive insight into behavior under field conditions. Drop weight impact testing is one type of laboratory study that has been proposed. Other types of testing that may be of use involve dynamic compressive testing of several samples that have been connected in series, and of cores that have already been deformed, to determine the mechanical capacity "leftover" after initial impact. Surlyn, in particular, has shown promise in this area, exhibiting a remarkable capacity to recover nearly its initial shape in a matter of seconds, even after being compressed dynamically in the Split Hopkinson Pressure Bar.

It appears that these novel core materials do hold promise in the force protection arena. The Air Force and each of the other services are constantly seeking materials that will provide necessary functionality, while contributing to the ability for forces to be rapidly mobile. Protection of manpower and critical equipment are essential components of our national defense, and the NorCore ${ }^{\circledR}$ materials may play a key role.

\section{References}

[1] Rice, Donald, Global reach - global power: the evolving air force contribution to national security, Air Force White Paper, December, 1992.

[2] America's Air Force Vision 2020, available via restricted-access military website.

[3] Phelps engineered plastics. Available from: www.pepcore.com.

[4] ASTM Standard C365, Standard test method for flatwise compressive properties of sandwich cores. Available from: www.astm.org. 